Reference: Franco-Santos, M. and Bourne, M. (2005), 'An Examination of the Literature Relating to Issues Affecting How Companies Manage Through Measures', Production Planning and Control, Vol. 16, No. 2, pp. 114-124.

\title{
An examination of the literature relating to issues affecting how companies manage through measures
}

\author{
Monica FRANCO-SANTOS ${ }^{1}$ and Mike BOURNE \\ Centre for Business Performance, Cranfield School of Management, \\ Cranfield, MK43 OAL, England
}

Keywords: Performance measurement systems, Performance measurement, Performance measures.

Abstract: In the last decade, organisations have devoted enormous time and effort to the development of Business Performance Measurement (BPM) systems. Many articles have been written on how to design and implement these type of systems. However, few studies have addressed the issue of why some organisations are better able to 'manage through measures' than others. In other words, why do some organisations struggle to ensure that action follows measurement, whilst others systematically use their metrics to inform their decision-making processes, and their subsequent actions? This paper aims to contribute to a more complete understanding of the use of BPM systems by reviewing the performance measurement literature developed in the management arena. It differs from previous examinations of performance measurement and management control systems in that it uses a broader scope and follows a new method of literature review applied to management research, namely, systematic review. The paper focuses on the thematic analysis of the review

\footnotetext{
${ }^{1}$ Corresponding author. Telephone: +44 (0) 1234751122 ext. 2926. Fax: +44 (0) 1234 757409. Email: monica.franco@cranfield.ac.uk
} 
only. The insights extracted from the literature are articulated and presented in a management framework. In addition, the paper identifies different gaps in the literature that require further research.

\section{Introduction}

Performance measurement is a fundamental cornerstone of modern management. Johnson $(1972,1975,1978,1981)$ from his studies of early manufacturing enterprises, came to the conclusion that its predecessor, management accounting, was a key enabler for the creation of modern manufacturing companies. It enabled the costing and co-ordination of production in multi-product wage paying factories; requirement not previously needed by cottage industries or domestic production systems. However, management accounting was also credited with the near destruction of Western manufacturing business (Hayes and Abernathy, 1980; Johnson and Kaplan, 1987) and the search for more appropriate tools led to the development of more balanced approaches to performance measurement (Lynch and Cross, 1991; Fitzgerald et al, 1991; Kaplan and Norton, 1992, 1996).

In the last two decades, significant effort has been directed at the development of processes for the design and implementation of performance measurement systems (Bitton, 1990; Eccles and Pyburn, 1992; Kaplan and Norton, 1993, 1996, 2000; Neely et al, 1996, 2000; Olve et al., 1999) and assessment of their fitness for purpose (Dixon et al., 1990; Bititci et al, 1998). However, only recently has a more critical literature developed, highlighting the problems with implementing performance measures (McCunn, 1998, Bourne et al, 2000, 2003a,b) and the longer-term problems with the use of performance measures (Meyer and Gupta, 1994; Townley et al, 2003) 
The current state of knowledge in performance measurement includes theoretical and practical understanding of the management processes required to design and implement performance measurement systems, and theoretical and practical knowledge of the main factors causing these processes to succeed or fail. Although we know how to develop and implement performance measurement systems, there is a gap in our knowledge: why are some organisations better able to manage through measurement than others? This research is of particular importance now as performance measurement systems such as the balanced scorecard are becoming widely used. If action does not follow measurement and the benefits are not realised most of the efforts being invested in scorecard implementations will be wasted.

In the light of this gap, the present paper aims to contribute to the existing knowledge on BPM systems by examining what are the factors that affect the ability of organisations to manage through measures. In order to identify those factors, we reviewed the literature on BPM systems, using a Systematic Review (Tranfield and Denyer, 2003). The paper will only focus on the thematic findings of this literature review and is structured as follows: first, the literature review methodology is briefly described; second, the thematic findings of our review are outlined; third, conclusions are presented, and areas for further research discussed.

\section{Methodology}

A Systematic Review is a novel research methodology characterised as being a methodical, transparent, and reproducible manner of analysing existing literature (Cook et al, 1997; Cooper, 1998). This methodology has been used in the medical sciences over the last fifteen years and it is now being applied to the management field (Tranfield and Denyer, 2003). A Systematic Review both maps and assesses the 
relevant literature and provides collective insights through the theoretical synthesis of a field. Systematic reviews differ significantly from traditional "narrative" reviews. Narrative reviews may often lack rigour, are more susceptible to researchers' bias, and in many cases are not undertaken as a genuine piece of investigatory science (Mulrow, 1987; Mulrow, 1994). In contrast, a Systematic Review can be defined as a genuine piece of investigatory science since it clearly specifies how the researcher conducts the review, what type of documents she/he reviews, and where those documents can be found. This allows other researchers to replicate the investigation.

The description of the step-by-step development of the systematic review has been omitted for clarity and conciseness. However a detailed presentation of this process can be found in Franco and Bourne (2003). Here the focus is on the method used for synthesising the literature reviewed. Once the search and study selection process (which involves the collection of relevant studies related to the topic of research) has been carried out, the information can be analysed either descriptively or thematically. The descriptive analysis helps to clarify the main characteristics of the field (methodologies used, classification of countries and industries studied, etc.). The main purpose of the thematic analysis, which consists of synthesising the main outcomes extracted from the literature, is to inform future research and practice. This paper only presents the latter.

The selected articles have been classified by applying Pettigrew's (1985) framework. Pettigrew's framework shows the factors that should be taken into account during a change management process. The framework contains three basic components: a context component, a process component, and an outcome component. The first component, the 'context', involves the identification of the contextual factors that 
influence or are being influenced by the process or system under examination; in this case a BPM system.

The second component, the 'process', involves the exploration of the process itself, which is seen as a continuous, interdependent, sequence of actions and events, and it is used to explain the origins, continuance, and outcome of some phenomena. Here, the process component is defined as the process of introducing a new BPM system into the organization. This process has a design stage, an implementation stage, and a use stage (Bourne et al, 2000). Finally, the third component, the 'outcome', involves the study of the end results of the process under investigation. In this paper, this third element relates to the effects BPM systems produce at different levels of the organization.

The main idea behind Pettigrew's framework is that organisational change processes can be better understood using a holistic or contextualist approach instead of a simplistic one, which only focuses on the episodic or on the change project. In a contextualist approach, the contextual factors or categories are linked to the process under observation. BPM systems cannot be fully understood using a narrow analysis perspective that only focuses on the single process of designing and/or implementing the system (e.g. Neely et al, 1995; Bourne et al, 2000). Instead, research on this type of systems should use a broad perspective. The review of the literature has been done with this principle in mind and its findings are presented below.

\section{Findings}

A BPM systematic review was developed between April 2002 and March 2003. The systematic review searches produced a total of 1563 studies. However, after applying 
inclusion and exclusion criteria, and carrying out a quality assessment exercise (for further details on this see Franco and Bourne, 2003) only 337 were included in the review. Of that list, only 73 studies that were considered to be relevant by the panel review have been used here.

For presenting the findings of the thematic analysis, we use the framework presented in Fig.1. It is based on Pettigrew's (1985) framework. The model is described in two phases. First, the different process and contextual factors that affect organisational outcomes are presented. Second, the potential impact of the use of BPM system on organisational outcomes is discussed.

\section{Take figure 1}

\subsection{Process factors}

The main process factors can be subdivided into those factors related to an effective design of a BPM system, those factors related to an effective implementation of a BPM system, and those factors related to the use of BPM systems (Bourne et al, 2000).

\subsubsection{Effective design of a BPM system}

There are many factors that enable an organisation to effectively design a BPM system. The following factors are critical.

- Performance measurement framework and strategy maps

Most authors agree on the need for a performance measurement framework such as the Balanced Scorecard, the Performance Prism or similar (Lingle and Schiemann, 1996; Maisel, 2001; Kaplan and Norton, 1992, 1996, 2001; Johnston et al, 2002; 
Neely et al., 2002). This framework has the role of providing a clear and balanced structure of the organisation's key performance dimensions. It has been pointed out (e.g. Ahn, 2001) that a BPM framework should be unique to the company involved. Furthermore, in recent years, the utilization of 'strategy maps' (Kaplan and Norton, 2000, 2001, 2004) also known as success maps (Neely and Bourne, 2000) or ActionProfit Linkage models (Epstein, 2001), as the basis of the performance measurement system has increased. According to Kaplan and Norton (2000) strategy maps let an organization describe and illustrate its strategic goals, initiatives, targets, performance measures, and the cause-and-effect relationships among all the pieces of its strategy. These maps formalise the idea proposed by Eccles and Pyburn (1992) regarding the creation of a mental business model as the first step for creating a testable strategy. The purpose of the strategic maps is mainly to facilitate the translation of strategy into operational terms (measures); and to help employees get a better understanding and a visual representation of the key factors upon which they need to focus.

Nevertheless, some authors (e.g. Norreklit, 2000, 2003; Ahn, 2001) have critically reviewed the apparent benefits of using strategy maps, highlighting issues such as the fact that these maps: do not discriminate among logical (e.g. two and two makes 4) and causal links (e.g. smoking causes cancer); do not include a possible time lag among measures; are overly simple and need to be validated (e.g. through statistical analysis); and ignore the fact that the different measurement perspectives (financial, customers, internal process, innovation \& learning) are not independent so feedback loops should be included. Moreover, there is the idea that strategies are continuously being redefined as the environment changes and knowledge base improves.

Consequently, there is no need for formal, long-standing strategic plans (Ahn, 2001; Lorange, 1998). These criticisms add value to our analysis; however, they are not 
supported by empirical evidence. Therefore it is difficult to assess the real impact of strategy maps.

\section{- Measures and targets}

Authors (e.g. Vasconcellos, 1988; Fitzgerald et al, 1991; Moon and Fitzgerald, 1996; Otley, 1999; Meliones, 2000; Busby and Williamson, 2000; Ahn, 2001; Kaplan and Norton, 2001; Malina and Selto, 2002) also agree on the importance of the identification and selection of the appropriate measures and targets at all levels of the organisation. It can be noted that one method of illustrating and plotting the above elements in such a way that helps employees and managers understand, which is the purpose of a performance measurement framework or of a strategy map; and another is choosing the measures and targets that would help the company to implement its intended strategy.

There are three important aspects regarding measures that have not been well researched in the BPM literature. First, Busby and Williamson (2000) argue that when designing measures "there has to be a concern with validity (the extent to which the measured quantities represent the constructs of interest) and reliability (the extent to which measurements are repeatable in various ways -for example, whether two observers would observe the same values at the same time)"; also with the fact that there is a strong trade-off between the two. Second, Palmer and Parker (2001), based on post-deterministic discoveries made in the physical sciences, especially quantum physics, claim that BPM systems should focus on aggregate measures since individual measurement is pointless. However, their approach is merely descriptive. Third, Ahn (2001) suggests that there are a few measurement requirements extracted from the decision-making literature (such as decomposability and non-redundancy) that could 
apply to the design of performance measures. Nevertheless, these requirements have been omitted in BPM literature. Overall, as areas of future research it would be worth while to look at these three aspects.

Many researchers find that target and milestone setting are critical in a BPM system design. However, guidelines regarding the identification and selection of these elements seem to be insufficient in the literature. Kaplan and Norton (1996), for example, only recommend the use of 'stretch targets' as does Manzoni (2002). Ahn (2001) proposes to take into account the interdependencies between the goals for quantifying the values of the measures to be attained each year. Johnston et al. (2001), in their study of 40 service firms in the UK, argue that most continuous improvement targets were based on past performance; that processes undergoing radical change made limited use of external benchmarks; and that, usually, targets were imposed by managers without consultation, with rewards linked to the achievement of those targets. These findings have several implications in BPM systems design. For instance, the fact that the lack of participation in target setting could be undermining the team-based empowerment philosophy of most strategies nowadays, and it could increase the level of resistance to the targets, in particular or to a BPM system in general. Furthermore, the idea that targets should not always be based on past performance. These few and rather ambiguous guidelines suggest that further research on this topic would be of great value to the field. In this sense, the accounting literature on setting budget targets (e.g. Murphy, 2000; Merchant and Manzoni, 1989) could be the place to start.

- Alignment and integration 
Another factor that performance measurement authors highlight is the need for alignment and integration when designing a BPM system (e.g. Bititci et al. 1997; Ghalayini et al, 1997). When authors stress the need for alignment in a BPM system they normally refer either to:

- vertical and horizontal alignment, which relates to the integration, linkage and cascading of mission, vision, and strategy and through process from supplier to customer; or to

- organisational systems alignment, which relates to the integration of a BPM system with other key management systems such as planning and budgeting, rewards, or information systems.

\section{- Information infrastructure}

A critical factor for the effective design of BPM systems is the process of identifying, selecting and developing an appropriate information infrastructure (Eccles, 1991; Lingle and Schiemann, 1996; Manoochehri, 1999). In this process the following aspects should be taken into account:

- The information needs of a BPM system and the procedures and rules to regulate the flow of information should be defined.

- The appropriate information system should be designed for collecting, analysing and reporting the data efficiently. Using an IT system to support these tasks seems to be critical (Meliones, 2000; Martins and Salerno, 1999). However, attention must be paid since the capabilities of technology in terms of data capture and manipulation provide a great temptation for senior management to introduce new measures (Wilson, 2000). 
- Accountability of the measures should be specified (Frigo and Krumwiede, 1999; Manoochehri, 1999), and as Eccles (1991) suggests, it is recommended that managers are assigned to each of the measures, or set of related measures and held responsible for developing its methodologies.

Regarding this factor, it has been noted that many companies that view non-financial measures as important are not capturing data on these measures (Stivers, 1998). The reasons could be the lack of information systems' capability to collect data or the fact that most of these measures are perceived to be immeasurable or difficult to measure and therefore useless (Manoochehri, 1999). Nevertheless, since non-financial measures have proved their value (e.g. Banker et al, 2000; Ittner and Larcker, 1998) there is a need for investing some effort in developing information systems that can actually process the measure of intangibles.

\subsubsection{Effective implementation of a BPM system}

A second set of factors that have an impact on the way organisations use their BPM system is the one related to the implementation process. Despite the plethora of papers and articles on the design of BPM systems, there is a dearth of academic studies focusing on implementation with most of the writing being based on practitioner experience (Bourne et al, 2003a). This phase is crucial as some authors suggest that $70 \%$ of performance measurement interventions fail (Lewy \& Du Mey, 1998, McCunn, 1998). Change management issues are certainly a factor (Bourne et al, 2003b) but these factors have not been well researched in the literature, although their impact can be even greater than the impact produced by the design factors (e.g. Roberts and Scapens, 1985). 
Implementation has been defined as the stage in which a BPM system and its procedures are put in place (Bourne et al, 2000). This stage is critical and it should not begin when the design stage finishes. Rather, it should overlap with both the design stage and the use stage. According to the literature, the factors that facilitate the effective implementation of BPM systems are very similar to the factors enabling change processes to occur (Kaplan and Norton, 2001; Bourne et al., 2003a,b). They are:

- Top manager agreement and commitment

In a series of longitudinal studies that focused primarily on performance measurement systems implementations, Bourne et al (2002) identified the main driver of implementation as being management agreement and commitment. Any BPM system implementation, as well as any change management process, should start with a clear agreement at the top on the strategy, goals, measures and the performance target to be implemented (Lingle and Schiemann, 1996; Gates, 1999; Maisel, 2001; Kaplan and Norton, 2001; Busby and Williamson, 2000). It is expected that top management team agreement would increase the level of their commitment and willingness to take the lead, which are critical for a BPM system success.

- The 3 E's: Empower, enable and encourage

To effectively implement a BPM system people must be empowered, enabled, and encouraged (Frigo and Krumwiede, 1999).

- Empower refers to the need for people's involvement in the development of a BPM system. Having the agreement, commitment and leadership at the top is insufficient if it does not go along with the agreement, commitment and leadership 
of the rest of the management team. Furthermore, the involvement of employees is also crucial (Lingle and Schiemann, 1996; Gates, 1999; Maisel, 2001; Johnston et al, 2002; Manoochehri, 1999; Boynton and Zmud, 1984). Additionally, it is also important to involve the Human Resources and the Information System functions in the development of a BPM system, since their expertise and knowledge of people management and technology respectively, is extremely useful (Meliones, 2000; Lorange, 1998).

- Enable refers to the need for people's education and training on the measures and on the related tools and procedures, e.g. data collection, analysis, interpretation, use of IT, etc. (Frigo and Krumwiede, 1999; Maisel, 2001; Kaplan and Norton, 2001).

- Encourage refers to the need for actions or activities that actually motivate people to use the data provided by a BPM system in their day-to-day work; create the right attitude towards the system; and reduce the level of resistance. These actions do not necessarily need to be formal (e.g. communication programmes, which will be discuss below); they can also be informal (e.g. through the example, leadership and commitment of the management team).

\section{- Communication}

Communication is one of the most cited factors in the literature (e.g. Forza and Salvador, 2000, 2001; Keasy et al., 2000). Most authors, when stressing the importance of communication, normally refer to the feedback of the measures' results to the employees. In addition, authors highlight the relevance of verbal and non-verbal communication (e.g. presentations, manuals, newsletters, reports, etc.) used to clarify all the aspects related to the measures in particular and a BPM system in general; and 
to facilitate the buy-in from the people in the organisation (Kaplan and Norton, 2001; Bourne et al., 2002).

\subsubsection{Effective use of BPM system}

The literature on the use of BPM system is not as extensive as the literature on the design of BPM systems. However, a few key factors that enable an organisation to better manage through measures can be identified.

\section{- Review and update}

Most authors emphasize the need for a continuous review of the measures themselves, (e.g. calculations, data collected) their results, and their impact on goals and strategy with a clear focus on improvement and learning (e.g. Lingle and Schiemann, 1996; Kaplan and Norton, 2001; Johnston et al, 2002; Neely et al, 2000; Ghalayini and Noble, 1996). Furthermore, authors suggest that a continual cleansing and renewal process of the measures included in the BPM system is required in order to keep them relevant for the organisation and its users (Frigo and Krumwiede, 1999; Manoochehri, 1999; Bourne et al, 2000; Kennerley and Neely, 2003).

- Data analysis, interpretation, decision-making and action taking

Managers must be able to turn data into insights (Neely and Bourne, 2000; Meliones, 2000; Smith and Goddard, 2002). In order to get insights it is critical to start a data review process with a business question in mind, then look for data that would give an answer to the formulated question, analyse the gathered data, make a decision based on the data analysis results, and finally, take some action.

\section{- Rewards}


A factor that has been widely researched in the accounting field but that is still in its initial stage in the literature on BPM systems is the linkage between total rewards and BPM systems. The few studies that exist on the impact of rewards on the use of BPM systems conflict in their findings. For instance, Kaplan and Norton (1996, 2001), Maisel (2001), Malina and Selto (2002) and Gates (1999), all suggest that the link between rewards and BPM systems is necessary to encourage the use of the system and achieve better perceived results. However, Ho and Mckay (2002) and Ittner and Larcker (2003a) argue that the use of the measures in a BPM system for reward purposes can increase subjectivity and therefore negatively affect the way in which the system is used.

- Performance measurement helping tools and management processes

Finally, studies such as Maisel's (2001) highlight the importance of developing tools and specific management processes that can facilitate the use of performance measures. Some examples could be the introduction of technical assistance for managers and employees; the development of quality forums, which can include the standardised measurement and reporting process to address inconsistencies and lack of comparative data (Ginsberg and Sheridan, 2001), or a specific process for reviewing the measures and ideally to agree action (Bourne et al, 2000).

\subsection{Contextual factors}

Only a few authors (e.g. Hoque and James, 2000) have paid attention to the contextual issues related to BPM systems. Using Pettigrew's (1985) framework contextual factors have been categorised as internal and external context factors. 


\subsubsection{Internal context factors}

Regarding the internal organisational context, most authors agree on the importance of firm strategy, culture, organisational size and organisational structure.

\section{- Firm strategy}

This factor is probably the most important of all, since a major role of a BPM system is to make sure that a firm strategy is being implemented and that it is still valid (Kaplan and Norton, 1992, 1996, 2001; Neely, 1998). However as Langfield-Smith (1997) argues, our knowledge of the relationship between Management Control Systems, including BPM systems, and strategy is limited. Empirical research has found that some strategies, such as the ones that focus on quality are more likely to encourage the use of BPM systems than others (Neely et al, 1994; Ittner and Larcker, 1997). Furthermore, based on studies in the field of strategic control by Goold and Campbell (1993) and Lorange (1998), it can be implied that for some companies the use of BPM systems might not be tenable (for example, the ones that manage a diverse portfolio of business which do not share common strategic characteristics or the ones that are continuously looking for new business).

\section{- Culture}

Mooraj et al. (1999) argue that BPM systems can be affected by national culture, occupational culture, and corporate culture. Other authors (Lingle and Schiemann, 1996; Gates, 1999; Maisel, 2001; Lockamy and Cox, 1995; Malina and Selto, 2002; Johnston et al, 2002) just suggest that BPM systems should be linked to the culture of the organisation. However, they do not provide any clear definition of what type of culture they refer to, nor how this alignment should be developed. 
Organisation structure is a key factor that directly affects the design of a BPM system and indirectly the implementation and use of measures (Manoochehri, 1999; Gates, 1999; Maisel, 2001; Lingle and Schiemann, 1996). For example, Hendricks (1996) shows how a large company went through an overhaul of its corporate structure and instituted performance measures appropriate for the new structure. Furthermore, organisational size also has an impact on the type of BPM system in use and its effectiveness. Hoque and James (2000) specifically analysed the relationship between organisational size and Balanced Scorecard. They found that as size increases, organizations find it more practical and useful placing greater emphasis on the BSC that supports their strategic decision making.

\subsubsection{External context factors}

Our review shows that few authors have focused their attention on the relationship between external contextual factors and BPM systems. One reason for the lack of research in this area could be that researchers make obvious assumptions regarding contextual factors (e.g. that profit and non-profit organisations are different contexts so they of course should have different ways of dealing with BPM systems). The few authors looking at contextual factors affecting the use of BPM systems (e.g. Smith and Goddard, 2002; Waggoner et al, 1999; Hussain and Hoque, 2002; Hoque and James, 2000) have tended to focus on:

- Industry characteristics. This factor relates to either monopoly or competitive market; public sector, regulated sector or competitive sector; and manufacturing or service sector. 
- Environment. This factor relates to demand uncertainty, supplier characteristics, or the economy.

\subsection{Impact of BPM system on outcomes}

So far this review has been based on the assumption that the use of BPM systems actually creates value (i.e. satisfaction of stakeholder needs and wants). A BPM system is thought to create value through the encouragement of the appropriate behaviours, which in turn are supposed to improve performance outcomes. However, it has only been recently that authors have started to test this assumption or parts of it. For example, Scott and Tiessen's (1999) study indicates that work teams having more diverse performance measures (i.e. both financial and non-financial measures or more categories of measures) achieve higher self-assessed performance (relative to expectations). Hoque and James (2000) also found a significant positive relation between organizational performance and the use of a diverse set of performance measures related to the four balanced scorecard categories. Sheu and Wacker (2001) found that fundamental manufacturing planning and control procedures improve a firm's performance on both its internal operations as well as external competitiveness goals. Ittner and Larcker's (2003b) study of 140 financial service firms found that firms which make more extensive use of a broader set of financial and non-financial measures than firms with similar strategies or value drivers, have higher measurement system satisfaction and stock market returns. Unfortunately, most of these studies are based on manager or employees' perception of achieved outcomes; or they only test some aspects of the impact of BPM systems on performance (e.g. the use of diverse measures). These two issues limit the ability to place substantive interpretations on their results. 


\section{Discussion and conclusions}

The findings obtained from this systematic review contribute to a better understanding of our existing knowledge on BPM systems. Our review suggests that there are eleven process factors and five context factors that facilitate a more effective use of BPM systems. The process factors have been grouped into three categories: design, implementation, and use factors. The context factors have been classified into internal and external factors. Overall, it has been suggested that sixteen factors have an impact on the way organisations manage through measures (see table A). Based on the literature, among these sixteen factors, the implementation ones are crucial.

\section{Take Table A}

Our findings have implications for researchers in the area of performance measurement; as well as for practitioners developing, implementing and using BPM systems in their organisations. For researchers, this list of factors can be used as the basis for further research. Moreover, we have found a number of specific issues related with these factors that need more investigation such as:

- the impact of strategy or success maps;

- certain characteristics of performance measures (e.g. validity, reliability, etc.);

- clear guidelines for target and milestone setting;

- relationship between BPM systems and other management systems;

- information infrastructures that are suitable for capturing non-financial information;

- additional context issues; and 
- the linkage between BPM systems and reward practices.

For practitioners, these sixteen factors can be used as a checking list of issues to take into account when designing, implementing and using a BPM system. Practitioners having a broad perspective of factors that affect how an organisation manages through measures, by focusing not only on process factors but also on context factors, are more likely to improve the effectiveness of their BPM system. However, this argument is based on the outputs of a literature review. Further empirical investigation is needed in order to provide evidence that supports this argument.

\section{Acknowledgements}

We thank the EPSRC for support of this project through the research grant, Managing through Measures (grant number GR/R56136/01).

\section{References}

AHN, H., 2001, Applying the balanced scorecard concept: an experience report, Long Range Planning, 34, (4), 441-461.

BANKER, R. D., POTTER, G., and SRINIVASAN, D., 2000, An empirical investigation of an incentive plan that includes non-financial performance measures, Accounting Review, 75, (1), 65-92.

BITITCI, U. S., CARRIE, A. S., and MCDEVITT, L., 1997, Integrated performance measurement systems: a development guide, International Journal of Operations \& Production Management, 17, (56), 522-534.

BITITCI, U. S., CARRIE, A. S., and TURNER, T., 1998, Diagnosing the integrity of your performance measurement system, Control, 9-13.

BITTON, M., 1990, Methode de conception et d'implantation de systmes de measure de performances pour organisations industrielles, Universita de Bordeaux I.

BOURNE, M., NEELY, A.D., MILLS, J.F., and PLATTS, K., 2003a, Implementing performance measurement systems: a literature review, International Journal of Business Performance Management, $5(1), 1-24$.

BOURNE, M., NEELY, A. D., MILLS, J. F., and PLATTS, K., 2003b, Why some performance measurement initiatives fail: lessons from the change management literature, International Journal of Business Performance Management, 5 (2/3), 245-269.

BOURNE, M., NEELY, A. D., MILLS, J. F., PLATTS, K., and WILCOX, M., 2000, Designing, implementing and updating performance measurement systems, International Journal of Operations \& Production Management , 20, (7), 754-771.

BOYNTON, A. C. and ZMUD, R. W., 1984, An assessment of critical success factors, Sloan Management Review, 25, (4), 17-27.

BUSBY, J. S. and WILLIAMSON, A., 2000, The appropriate use of performance measurement in non- 
production activity - the case of engineering design, International Journal of Operations \& Production Management, 20, (3-4), 336-358.

COOK, D. J., MULROW, C. D., and HAYNES, R. B., 1997, Systematic reviews: synthesis of best evidence for clinical decisions, Annals of Internal Medicine, 126, (5), 376-380.

COOPER, H., 1998, Synthesizing research, (Thousand Oaks, CA: Sage Publications, Inc.).

DIXON, J. R., NANNI, A. J., and VOLLMANN, T. E., 1990, The new performance challenge measuring operations for world-class competition, (Homewood, Illinois: Dow Jones-Irwin).

ECCLES, R. G., 1991, The performance measurement manifesto, Harvard Business Review, 131-137.

ECCLES, R. G. and PYBURN, P. J., 1992, Creating a comprehensive system to measure performance, Management Accounting, October ), 323.

EPSTEIN, M. J., 2001, Linking actions to profits in strategic decision making, Sloan Management Review, 42, (3), 39.

FITZGERALD, L., JOHNSTON, R., SILVESTRO, R., VOSS, C., and BRIGNALL, T. J., 1991, Performance measurement in service business, Management Accounting, 69, (10), 34.

FORZA, C. and SALVADOR, F., 2000, Assessing some distinctive dimensions of performance feedback information in high performing plants, International Journal of Operations \& Production Management, 20, (3), 359-385.

FORZA, C. and SALVADOR, F., 2001, Information flows for high-performance manufacturing, International Journal of Production Economics, 70, (1), 21-36.

FRANCO, M., and BOURNE, M., 2003, EurOMA Annual Conference, Como, Italy,

FRIGO, M. L. and KRUMWIEDE, K. R., 1999, Balanced scorecards: A rising trend in strategic performance measurement, Journal of Strategic Performance Measurement, 42-48.

GATES, S., 1999, Aligning strategic performance measures and results, (New York, US: The Conference Board).

GHALAYINI, A. M. and NOBLE, J. S., 1996, The changing basis of performance measurement, International Journal of Operations \& Production Management, 16, (8), 63-80.

GHALAYINI, A. M., NOBLE, J. S., and CROWE, T. J., 1997, An integrated dynamic performance measurement system for improving manufacturing competitiveness, International Journal of Production Economics, 48, (3), 207-225.

GINSBERG, C. and SHERIDAN, S., 2001, Limitations of and barriers to using performance measurement: purchaser's perspective, Health Care Financing Review, 22, (3), 49-57.

GOOLD, M., CAMPBELL, A., and LUCHS, K., 1993, Strategies and styles revisited - strategic control - is it tenable, Long Range Planning, 26, (6), 54-61.

HAYES, R. H. and ABERNATHY, W. J., 1980, Managing our way to economic decline, Harvard Business Review, 67-77.

HENDRICKS, J. A. E. AL., 1996, Changing performance measures at Caterpillar, Management Accounting, 18-24.

HO, S.-J. K. and MCKAY, R. B., 2002, Balanced scorecard: two perspectives, The CPA Journal, 72, (3), 20-25.

HOQUE, Z. and JAMES, W., 2000, Linking balanced scorecard measures to size and market factors: Impact on organizational performance, Journal of Management Accounting Research, 12, 1-17.

HUSSAIN, M. and GUNASEKARAN, A., 2002, Management accounting and performance measures in Japanese banks, Managing Service Quality, 12, (4), 232-245.

ITTNER, C. D. and LARCKER, D. F., 1998, Are non-financial measures leading indicators of financial performance? An analysis of customer satisfaction, Journal of Accounting Research, 36, 1-35.

ITTNER, C. D. and LARCKER, D. F., 1997, Quality strategy, strategic control systems, and organizational performance, Accounting, Organizations and Society, 22, (3-4), 293-314.

ITTNER, C. D., LARCKER, D. F., and MEYER, M. W., 2003a, Subjectivity and the weighting of 
performance measures: evidence form a balanced scorecard, Accounting Review, 78, (3), 725-758.

ITTNER, C. D., LARCKER, D. F., and RANDALL, T., 2003b, Performance implications of strategic performance measurement in financial service firms, Accounting, Organizations and Society, 28, (7-8), 715-741.

JOHNSON, H. T., 1972, Early cost accounting for internal management control: lyman mills in the 1850s, Business History Review, 466-474.

JOHNSON, H. T., 1975, Management accounting in early integrated industry: e.i. Dupont de nemours powder company, 1903-1912, Business History Review, 184-204.

JOHNSON, H. T., 1978, Management accounting in an early multidivisional organisation: general motors in the 1920s, Business History Review, 490-517.

JOHNSON, H. T., 1981, Toward a new understanding of nineteenth-century cost accounting, The Accounting Review, 510-518.

JOHNSON, H. T. and KAPLAN, R. S., 1987, Relevance lost: The rise and fall of management accounting, (Boston, MA: Harvard Business School Press).

JOHNSTON, R., BRIGNALL, S., and FITZGERALD, L., 2002, 'Good enough' performance measurement: a trade-off between activity and action, Journal of the Operational Research Society, 53, (3), 256-262.

JOHNSTON, R., FITZGERALD, L., MARKOU, E., and BRIGNALL, S., 2001, Target setting for evolutionary and revolutionary process change, International Journal of Operations \& Production Management, 21, (11), 1387-1403.

KAPLAN, R. and NORTON, D., 2004, Strategy maps: converting intangible assets into tangible outcomes, (Boston, MA: Harvard Business School Press).

KAPLAN, R. S. and NORTON, D. P., 1992, The balanced scorecard - measures that drive performance, Harvard Business Review, 70, (1), 71-79.

KAPLAN, R. S. and NORTON, D. P., 1993, Putting the balanced scorecard to work, Harvard Business Review, 71, (5), 134-142.

KAPLAN, R. S. and NORTON, D. P., 1996, The balanced scorecard - translating strategy into action, (US, Boston, Mass.: Harvard Business School Press).

KAPLAN, R. S. and NORTON, D. P., 2000, Having trouble with your strategy? Then map it, Harvard Business Review, 78, (5), 167-+.

KAPLAN, R. S. and NORTON, D. P., 1996, Linking the balanced scorecard to strategy, Harvard Business Review, 39, (1), 53-79.

KAPLAN, R. S. and NORTON, D. P., 2001, The strategy-focused organization: how balanced scorecard companies thrive in the new business environment, (Boston, MA: Harvard Business School Press).

KEASEY, K., MOON, P., and DUXBURY, D., 2000, Performance measurement and the use of league tables: Some experimental evidence of dysfunctional consequences, Accounting and Business Research, 30, (4), 275-286.

KENNERLEY, M. P. and NEELY, A. D., 2002, A framework of the factors affecting the evolution of performance measurement systems, International Journal of Operations \& Production Management, 22, (11), 1222-1245.

LANGFIELDSMITH, K., 1997 , Management control systems and strategy: a critical review, Accounting, Organizations and Society, 22, (2), 207-232.

LEWY and DU MEE, 1998, The ten commandments of balanced scorecard implementation, Management Control and Accounting, April.

LINGLE, J. H. and SCHIEMANN, W. A., 1996, From balanced scorecard to strategic gauges: Is measurement worth it?, Management Review, 56-62.

LOCKAMY, A. and COX, J. F., 1995, An empirical study of division and plant performance measurement systems in selected world-class manufacturing firms - linkages for competitive 
advantage, International Journal of Production Research, 33, (1), 221-236.

LORANGE, P., 1998, Strategy implementation: the new realities, Long Range Planning, 31, (1), 1829.

LYNCH, R. L. and CROSS, K. F., 1991, Measure up - The essential guide to measuring business performance, (London: Mandarin).

MAISEL, L. S., 2001, Performance measurement practices survey results, (US: AICPA).

MALINA, M. A. and SELTO, F. H., 2002, Communicating and controlling strategy: an empirical study of the effectiveness of the balanced scorecard, Journal of Management Accounting Research, 13, 47.

MANOOCHEHRI, G., 1999, Overcoming obstacles to developing effective performance measures , Work Study, 48, (6), 223-229.

MANZONI, J.-F., 2002, Management control: Toward a new paradigm? In M. J. Epstein and J.-F. Manzoni, Performance Measurement and management control: a compendium of research, (Kidlington, Oxford, UK: Elsevier Science Ltd.), pp. 15-46.

MARTINS, R. A., and SALERNO, M. S., 1999, Managing operations networks, (EurOMA Conference: Italy).

MCCUNN, P., 1998, The balanced scorecard: the eleventh commandment, Management Accounting, 34-36.

MELIONES, J., 2000, Saving money, saving lives, Harvard Business Review, 78, (6), 57-+.

MERCHANT, K. A. and MANZONI, J. F., 1989, The achievability of profit center budget targets: a field study, Accounting Review, 539-558.

MEYER, M. W. and GUPTA, V., 1994, The performance paradox, Research in Organizational Behavior, 16, 309-369.

MOON, P. and FITZGERALD, L., 1996, Delivering the goods at TNT: The role of the performance measurement system, Management Accounting Research, 7, (4), 431-457.

MOORAJ, S., OYON, D., and HOSTETTLER, D., 1999, The balanced scorecard: A necessary good or an unnecessary evil?, European Management Journal, 17, (5), 481-491.

MULROW, C. D., 1987, The medical review article: State of the science, Annual International Medicine, 106, 485-488.

MULROW, C. D., 1994, Systematic reviews Rationale for Systematic Reviews, British Medical Journal, 309, (6954), 597-599.

MURPHY, K. J., 2000, Performance standards in incentive contracts, Journal of Accounting \& Economics, 30, (3), 245-278.

NEELY, A. D., MILLS, J., PLATTS, K., GREGORY, M., and RICHARDS, H., 1994, Realising strategy through measurement, International Journal of Operations \& Production Management, 14, (3), 140-152.

NEELY, A. D., 1998, Three modes of measurement: Theory and practice, International Journal of Business Performance Management, 1, (1), 47-64.

NEELY, A. D., ADAMS, C., and KENNERLEY, M., 2002, The performance prism: the scorecard for measuring and managing business success, (London, UK: Pearson Education Ltd.).

NEELY, A. D. and BOURNE, M., 2000, Why measurement initiatives fail, Measuring Business Excellence, 4, (4), 3-6.

NEELY, A. D., MILLS, J. F., PLATTS, K., GREGORY, M. J., and RICHARDS, H., 1996, Performance measurement system design: Should process based approaches be adopted?, International Journal of Production Economics, 46, 423-431.

NEELY, A. D., GREGORY, M. J., and PLATTS, K., 1995, Performance measurement system design: a literature review and research agenda, International Journal of Operations \& Production Management, 15, (4), 80-116. 
NEELY, A. D., MILLS, J. F., PLATTS, K., RICHARDS, H., GREGORY M.J., BOURNE, M., and KENNERLEY, M. P., 2000, Performance measurement system design: developing and testing a process-based approach, International Journal of Operations \& Production Management, 20, (10), 1119-1145.

NORREKLIT, H., 2000, The balance on the balanced scorecard - a critical analysis of some of its assumptions, Management Accounting Research, 11, (1), 66-88.

NORREKLIT, H., 2003, The balanced scorecard: what is the score? A rhetorical analysis of the Balanced Scorecard., Accounting, Organizations and Society, 28, (6), 591.

OLVE, N.-G., ROY, J., and WETTER, M., 1999, A practical guide to using the balanced scorecard, (Chichester: Wiley).

OTLEY, D. T., 1999, Performance management: a framework for management control systems research, Management Accounting Research, 10, (4), 363-382 .

PALMER, E. and PARKER, D., 2001, Understanding performance measurement Systems Using physical science uncertainty principles, International Journal of Operations \& Production Management, 21, (7), 981-999.

PETTIGREW, A. M., 1985, The awakening giant: continuity and change in Imperial Chemical Industries, (Oxford, UK: Blackwell).

ROBERTS, J. and SCAPENS, R., 1985, Accounting systems and systems of accountability understanding accounting practices in their organizational contexts, Accounting, Organizations and Society, 10, (4), 443-456.

SCOTT, T. W. and TIESSEN, P., 1999, Performance measurement and managerial teams, Accounting, Organizations and Society, 24, (3), 263-285.

SHEU, C. W. and WACKER, J. G., 2001, Effectiveness of planning and control systems: an empirical study of US and Japanese firms, International Journal of Production Research, 39, (5), 887-905.

SMITH, P. C. and GODDARD, M., 2002, Performance management and operational research: a marriage made in heaven?, Journal of the Operational Research Society, 53, (3), 247-255.

STIVERS, B. P. E. AL., 1998, How non-financial performance measures are used, Management Accounting, 44-47.

TOWNLEY, B., COOPER, D. J., and OAKES, L., 2003, Performance measures and the rationalization of organizations, Organization Studies, 24, (7), 1045-1071.

TRANFIELD, D. and DENYER, D., 2003, Towards a methodology for developing evidence-informed management knowledge by means of systematic review, British Journal of Management, 14, (3), 207222.

VASCONCELLOS, J., 1988, The impact of key success factors on company performance, Long Range Planning, 21, (6), 56-64.

WAGGONER, D. B., NEELY, A. D., and KENNERLEY, M. P., 1999, The forces that shape organisational performance measurement systems: an interdisciplinary review, International Journal of Production Economics, 60, (1), 53-60.

WILSON, A., 2000, The use of performance information in the management of service delivery, Marketing Intelligence \& Planning, 18, (3), 127-134. 


\section{Figures}

Figure 1. Managing through measures

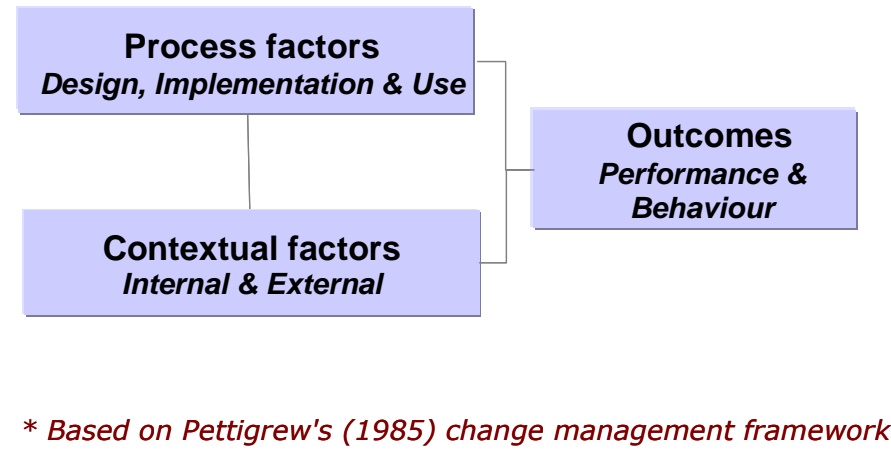

\section{Tables}

Table A. Summary

\begin{tabular}{|c|c|c|}
\hline Categories & Factors & Sub-factors \\
\hline \multirow[t]{3}{*}{ Process } & Design & $\begin{array}{l}\text { - BPM framework and strategy map } \\
\text { - } \text { Measures \& targets } \\
\text { - Alignment and integration } \\
\text { - Information infrastructure }\end{array}$ \\
\hline & Implementation & $\begin{array}{l}\text { - Top management agreement, commitment } \\
\text { - The } 3 \text { E's: Empower, enable and encourage } \\
\text { - Communication }\end{array}$ \\
\hline & Use & $\begin{array}{l}\text { - Review and update measures } \\
\text { - Data analysis, interpretation, decision-making } \\
\text { and action taking } \\
\text { - Rewards } \\
\text { - Performance measurement helping tools and } \\
\text { management processes }\end{array}$ \\
\hline \multirow[t]{2}{*}{ Context } & Internal & $\begin{array}{l}\text { - } \text { Firm strategy } \\
\text { - Culture } \\
\text { - Organisational structure \& size }\end{array}$ \\
\hline & External & $\begin{array}{l}\text { - Industry } \\
\text { - Environment }\end{array}$ \\
\hline
\end{tabular}

